PROC. OF JSCE,

No. 289, SEPT. 1979

\title{
ON THE CHARACTERISTICS OF SURFACE RUNOFF IN THE FLAT LAND
}

\author{
By MD. Sayeedul Islam KHAN*, Fusetsu TAKAGI** \\ and Shohei $A D A C H I^{* * *}$
}

\section{INTRODUCTION}

In many parts of the world surface drainage after a heavy rainfall poses a great problem. Problem of drainage is more acute on flat land because of less outflow and more surface detention. On these problems numerous research works have been made by means of the lumpedsystem models. For instance, the rice field regions and/or the main channel reaches have often been treated as simple hydraulic reservoirs or tanks ${ }^{9}$. The assumptions are, however, conceptual and have not been discussed in details based on the hydraulic behaviour of water flow in the region. That is, the so-called dischargestorage relationship is assumed as simple functions in many cases and on this basis the discharge hydrograph has been simulated. However, the coefficients involved in the discharge-storage relation must be estimated by using the numerous observed hydrologic data in the watershed concerned. Although the method is very practical for the brief treatment of runoff phenomena, there are some difficulties in applying it to the watershed with no observed data and also to the drainage plannings in such a region where the values of several hydrologic characteristics will vary due to the construction of new artificial drainage systems. Moreover, the problems as to whether any region may be treated as a lumped model or must be described by the distributed model have not been clarified in connection with the physical features of phenomena within the

* Assoc. Prof., Dept. of Civil Engineering Rajshahi Engineering College, Bangladesh.

** Prof., Dr., Dept. of Civil Engineering, Nagoya Univ.

*** Prof., Dr., Dept. of Civil Engineering Nagoya Univ. region.

On the other hand, the kinematic wave method $^{10), 11)}$ has also been proposed for the runoff analysis in the flat land. However, the basic conception of applying this method can not be clearly explained with respect to the problem of whether the kinematic wave method for the uni-directional flow system may be applied to the water behaviour in the flat land. Moreover, the main parameter, so called equivalent roughness coefficient, must be estimated by the observed field data.

With this situation, the authors have attempted to discuss the hydraulic behaviours of water flow by solving the fundamental equations as the distributed system and then to clarify the criteria of lumping the distributed system into a lumped system. For this purpose, the fundamental equations for the overland and channel flows are rewritten into the non-dimensional forms with respect to the spatially or gradually varied flow problems. The numerical solutions of these equations with two characteristic parameters are obtained to examine the dischargestorage relationship in general terms. Thereafter, the applicability of the storage-discharge relation is also discussed.

\section{FUNDAMENTAL EQUATIONS}

The elemental watershed for the runoff process may be generally expressed by the model as shown in Fig. 1. The model consists of runoff picture of overland field and channel reach and for the brief treatment of the phenomena the rectangular overland region and the channel of constant width are considered here. The physical processes of flow in the model are treated mathematically as one-dimensional flow with lateral inflow to both overland and channel flow systems. Therefore, the fundamental equations ${ }^{2), 6)}$ for both the 


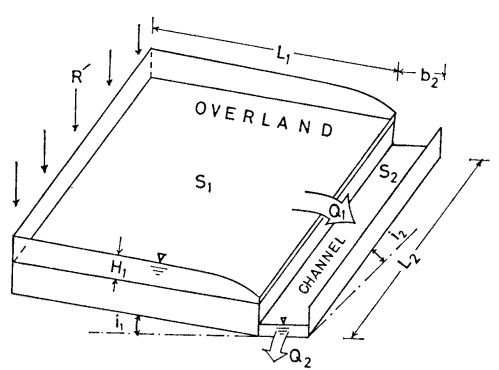

Fig. 1 Model picture of overland and channel runoffs.

systems are expressed in the following forms of continuity and momentum equations.

$$
\begin{aligned}
& \frac{\partial h}{\partial t}+\frac{\partial(u h)}{\partial x}=r, \quad \ldots \ldots \ldots \ldots \ldots \ldots \ldots \ldots \ldots \ldots \\
& \frac{1}{g}\left(\frac{\partial u}{\partial t}+u \frac{\partial u}{\partial x}\right)+\frac{\partial h}{\partial x}-i+i_{f}=0 . \cdots
\end{aligned}
$$

where $t$ : time, $x$ : distance along flow plane, $h$ : flow depth, $u$ : flow velocity, $r$ : lateral inflow, $g$ : acceleration due to gravity, $i$ : bed slope and $i_{f}$ : friction slope. In the above equation (2), the momentum carried into the main flow by the lateral inflow is very small and is neglected ${ }^{8)}$. From Manning's relation $i_{f}$ is evaluated as

$$
i_{f}=\frac{n^{2} u^{2}}{h^{4 / 3}} \text {. }
$$

Here, the following boundary conditions are adopted for the above set of fundamental equations. For the upstream and down-stream ends it is, respectively, considered that

$$
\left.\begin{array}{lll}
u=0 & \text { at } & x=0, \\
u=\sqrt{g h} & \text { at } & x=L .
\end{array}\right\}
$$

It is also considered that there is no flow before the occurrence of rainfall and as such

$$
u=0 \text { and } h=0 \text { at } t=0 \text {. }
$$

Now, in order to convert Eqs. (1) and (2) to non-dimensional form ${ }^{7}$ the normalizing operators $^{5)} x^{*}, h^{*}$ and $t^{*}$ are chosen respectively for $x$, $h$ and $t$. Then the quantities of distance, depth, time, velocity and slope are expressed as

$$
\begin{aligned}
& x=x^{*} \cdot X, \quad h=h^{*} \cdot H, \quad t=t^{*} \cdot T, \\
& u=\frac{x^{*}}{t^{*}} \cdot U, \quad i=\frac{h^{*}}{x^{*}} \cdot I, \\
& i_{f}=\frac{n^{2} x^{* 2}}{t^{* 2} h^{* 4 / 3}} \cdot \frac{U^{2}}{H^{4 / 3}},
\end{aligned}
$$

where $X, H, T, U$ and $I$ are the corresponding non-dimensional quantities.

Let $r^{*}$ be the normalizing operator for converting the lateral inflow to non-dimensional quantities, then we have

$$
r=r^{*} \cdot R
$$

where $R$ : non-dimensional lateral inflow and corresponds to the rainfall excess intensity $R^{\prime}$ for the overland field and the lateral inflow rate from the overland field $Q_{1}$ for the channel. Now, from the above expressions, the fundamental equations (1) and (2) take the following nondimensional forms.

$$
\begin{aligned}
& \frac{\partial H}{\partial T}+\frac{\partial(U H)}{\partial X}=\theta R, \quad \ldots \ldots \ldots \ldots \ldots \ldots \ldots \ldots . . . . . . \\
& \frac{\partial U}{\partial T}+U \frac{\partial U}{\partial X}+\epsilon\left(\frac{\partial H}{\partial X}-I\right)+\lambda \frac{U^{2}}{H^{4 / 3}}=0,
\end{aligned}
$$

where

$$
\left.\begin{array}{l}
\theta=r^{*} \cdot \frac{t^{*}}{h^{*}}, \\
\epsilon=g h^{*} \frac{t^{* 2}}{x^{* 2}}, \\
\lambda=g n^{2} \cdot \frac{x^{*}}{h^{* 4 / 3}} .
\end{array}\right\}
$$

Equations (3) and (9) show that the flow behaviour is characterized by three non-dimensional coefficients $\epsilon, \theta$ and $\lambda$. While of the four normalizing operators $x^{*}, h^{*}, t^{*}$ and $r^{*}$, which formulate the three non-dimensional coefficients, two may be chosen independently, since these operators involve only two fundamental dimensions "length" and "time". Moreover, the mutual relationships among the four operators are constrained by Eq. (10). Therefore, in the mathematical meaning, we may choose the appropriate set of values of the four operators so that any two among the non-dimensional coefficients $\epsilon$, $\theta$ and $\lambda$ become equal to unity.

In the present paper, as the attention is focused to the physical process of the flow, it is convenient to choose the operators $x^{*}$ and $r^{*}$ in connection with the basin scale and the input characteristics as

$$
\begin{aligned}
& x^{*}=L_{j}, \\
& r^{*}=\bar{r}_{j},
\end{aligned}
$$

in which the suffices $j=1,2$ denote the quantities for the overland and channel flow systems, respectively. $\bar{r}_{1}$ for the overland denotes the mean rainfall excess. As the width of flow between the overland and channel differes, $\bar{r}_{2}$ for the channel is written in terms of the mean rainfall excess $\bar{r}_{1}$ and a new operator $\beta$ as

$$
\bar{r}_{2}=\beta \bar{r}_{1}
$$

where $\beta$ is the ratio of the overland flow length $L_{1}$ to the channel width $b_{2}$, that is, 


$$
\beta=L_{1} / b_{2}
$$

And thus, for the set of the values of

$$
\theta=1, \lambda=1 \text {, }
$$

the other operators $h^{*}, t^{*}$ and $\epsilon$ are defined as

$$
\begin{aligned}
& h^{*}{ }_{j}=\left(g n_{j}{ }^{2} L_{j}\right)^{3 / 4}, \\
& t^{*}{ }_{j}=\frac{\left(g n_{j}{ }^{2} L_{j}\right)^{3 / 4}}{\bar{r}_{j}},
\end{aligned}
$$

and

$$
\epsilon_{j}=\frac{g^{13 / 4} n_{j}^{9 / 2} L_{j}^{1 / 4}}{\bar{r}_{j}^{2}} .
$$

With the help of these relationships (15)(18), finally the equations (8) and (9) may be rewritten as

$$
\begin{aligned}
& \frac{\partial H_{j}}{\partial T_{j}}+\frac{\partial\left(U_{j} H_{j}\right)}{\partial X_{j}}=R_{j} \cdots \cdots \cdots \cdots \cdots \cdots \cdots \cdots \cdots \cdots \cdots \cdots \cdots \\
& \frac{\partial U_{j}}{\partial T_{j}}+U_{j} \frac{\partial U_{j}}{\partial X_{j}}+\epsilon_{j}\left(\frac{\partial H_{j}}{\partial X_{j}}-I_{j}\right)+\frac{U_{j}^{2}}{H_{j}{ }^{4 / 3}}=0,
\end{aligned}
$$

in which the suffices $j=1,2$ indicate the quantities for the overland flow and the channel flow, respectively. The quantity $I_{j}$ in the third term of Eq. (20) is given by

$$
I_{j}=\frac{i_{j} L_{j} j^{1 / 4}}{g^{3 / 4} n j^{3 / 2}}
$$

In terms of the non-dimensional parameters introduced above, the boundary and initial conditions expressed by Eqs. (4) and (5) take the following forms.

$$
\left.\begin{array}{ll}
U_{j}=0 & \text { at } X_{j}=0 \\
U_{j}=\sqrt{\epsilon_{j} H_{j}} & \text { at } X_{j}=1 \\
U_{j}=0, H_{j}=0 & \text { at } T_{j}=0
\end{array}\right\}
$$

The equations (19) and (20) and the boundary and initial conditions expressed by Eq. (22) govern the flow processes of overland flow system $(j=1)$ and the channel flow system $(j=2)$. From these equations it is clearly understood that the characteristics of the flow processes in the elemental watershed depend on the two nondimensional parameters $\epsilon$ and $I$. By calculating various hydraulic quantities for several sets of values of $\epsilon$ and $I$, discharge hydrographs, water profile, storage-discharge relation etc. are obtained. The general features of the runoff process in the overland and channel systems are then discussed to generalize this study for any basin having similar basin characteristics.

\section{NUMERICAL SOLUTIONS}

\section{(1) Lax-Wendroff Scheme}

The 2-step Lax-Wendroff method $^{3)}$ is used for the solution of both overland and channel flow equations. The 2-step Lax-Wendroff method is a method of central finite difference, but the time increment $\Delta T$ is advanced in two steps. In this way, the technique considers accuracy up to second order in Taylor's expansion series ${ }^{1}$, and this minimizes the error and increases the stability of the solution. The calculations are done with the help of a high speed digital computer.

\section{(2) Flow parameters and conditions}

There are only two parameters $\epsilon$ and $I$ in the non-dimensional equations (19) and (20) for overland and channel flow systems. These two parameters contain the roughness factor $n$, gravitational acceleration $g$, flow length $L$, bed slope $i$, mean rainfall excess $\vec{r}_{1}$ and $\beta$. The term $\beta$ is considered only in the case of channel flow, and $\beta=100$ is considered throughout the calculation herein.

a) Parameter $\epsilon$

The characteristics of parameter $\epsilon$ may be explained in relation to Froude number. From Eq. (10) it is seen that $\epsilon$ is equal to the inverse of the square of Froude number. Fig. 2 shows the graphical representation of $\epsilon$ in Eq. (18) in combination with $L, n$ and $\vec{r}_{1}$. This graph is for the overland system and for the usual overland flow the magnitudes of $\epsilon_{1}$ lie between $10^{6} \sim$ $10^{8}$. Similar graph may also be prepared for the channel system and the value of $\epsilon_{2}$ for the channel system ranges between $10^{2} \sim 10^{4}$.

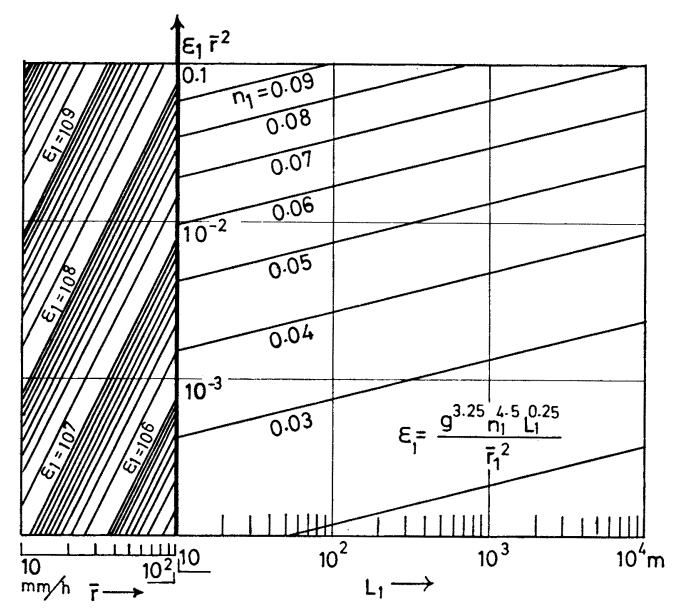

Fig. 2 Graphical representation of $\epsilon_{1}$ in combination with $L, n$ and $\bar{r}$.

b) Parameter I

From Eq. (6) it is found that the parameter 


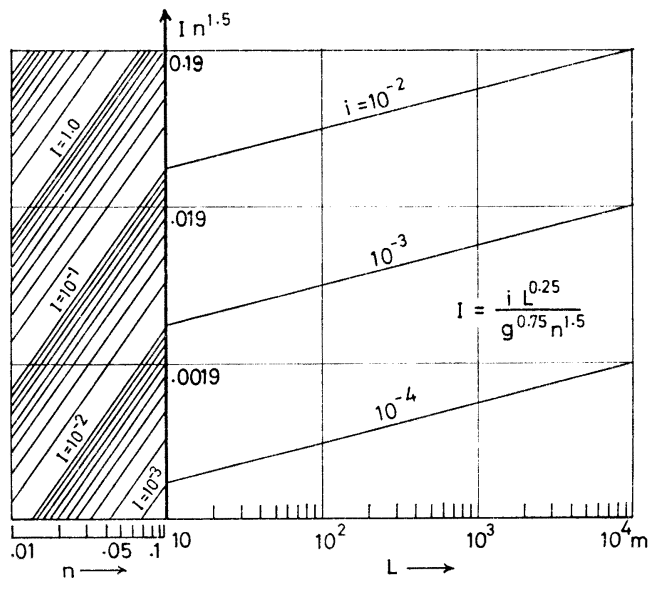

Fig. 3 Graphical representation of $I$ in combination with $i, L$ and $n$.

$I$ is the ratio of bed slope $i$ to some characteristic slope $i_{*}\left(=h^{*} / x^{*}\right)$. Fig. 3 shows the graphical representation of $I$ in Eq. (21) in combination with $i, L$ and $n$. This graph is for both overland and channel flow systems and usually the magnitudes of $I$ lie between $10^{-3} \sim 1.0$.

c) Rainfall condition

Three types of rainfall as shown in Fig. 4 are used in the calculation and the various rainfall duration $T_{R}$ is applied. Any magnitude of $\tilde{r}_{1}$ is good for this solution.
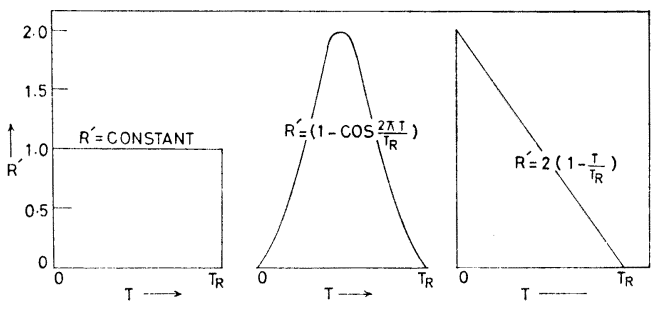

Fig. 4 Rainfall patterns.

Magnitudes of the parameters corresponding to several runs are shown in Tables 1 and 2 for the overland and channel systems, respectively.

d) Boundary condition

In Japan free fall condition at the outlet is not generally found. But due to different topographic and hydrologic conditions, for instance in Bangladesh the outlet condition is generally considered as free fall. In this study, free fall and as such critical condition of flow is considered at the outlet of both overland and channel. However, the method of solution adopted in this study may also be extended to other types
Table 1 Overland flow.

\begin{tabular}{|c|c|c|c|c|c|}
\hline Run & $\varepsilon_{1}$ & $I_{1}$ & $R^{\prime}$ & $T_{R}$ & Remarks \\
\hline 1 & $10^{6}$ & 0 & 1.0 & $\begin{array}{l}0.03,0.06 \\
0.09,0.12\end{array}$ & $\begin{array}{l}\text { Four Sub- } \\
\text { runs }\end{array}$ \\
\hline 2 & $10^{6}$ & 0 & $\left(1-\cos 2 \pi T / T_{R}\right)$ & 0.25 & \\
\hline 3 & $10^{6}$ & 0 & $2\left(1-T / T_{R}\right)$ & 0.25 & \\
\hline 4 & $10^{7}$ & 0 & 1.0 & $\begin{array}{l}0.02,0.04, \\
0.06,0.072\end{array}$ & $\begin{array}{l}\text { Four Sub- } \\
\text { runs }\end{array}$ \\
\hline 5 & $10^{7}$ & 0 & $\left(1-\cos 2 \pi T / T_{R}\right)$ & $\begin{array}{l}0.036,0.072 \\
0.144\end{array}$ & $\begin{array}{l}\text { Three Sub- } \\
\text { runs }\end{array}$ \\
\hline 6 & $10^{7}$ & 0 & $2\left(1-T / T_{R}\right)$ & $\begin{array}{l}0.036, \\
0.144\end{array}$ & $\begin{array}{l}\text { Three Sub- } \\
\text { runs }\end{array}$ \\
\hline 7 & $10^{7}$ & $10^{-2}$ & 1.0 & 0.12 & \\
\hline 8 & $10^{7}$ & $10^{-1}$ & 1.0 & 0.03 & \\
\hline 9 & $10^{7}$ & 1.0 & 1.0 & 0.027 & \\
\hline 10 & $10^{7}$ & $10^{-2}$ & $\left(1-\cos 2 \pi T / T_{R}\right)$ & 0.14 & \\
\hline 11 & $10^{7}$ & $10^{-1}$ & $\left(1-\cos 2 \pi T / T_{R}\right)$ & 0.055 & \\
\hline 12 & $10^{7}$ & 1.0 & $\left(1-\cos 2 \pi T / T_{R}\right)$ & 0.027 & \\
\hline 13 & $10^{7}$ & $10^{-2}$ & $2\left(1-T / T_{R}\right)$ & 0.14 & \\
\hline 14 & $10^{7}$ & $10^{-1}$ & $2\left(1-T / T_{R}\right)$ & 0.055 & \\
\hline 15 & $10^{7}$ & 1.0 & $2\left(1-T / T_{R}\right)$ & 0.027 & \\
\hline 16 & $10^{8}$ & 0 & 1.0 & $\begin{array}{l}0.01,0.02, \\
0.03,0.04\end{array}$ & $\begin{array}{l}\text { Four Sub- } \\
\text { runs }\end{array}$ \\
\hline 17 & $10^{8}$ & 0 & $\left(1-\cos 2 \pi T / T_{R}\right)$ & 0.09 & \\
\hline 18 & $10^{8}$ & 0 & $2\left(1-T / T_{R}\right)$ & 0.09 & \\
\hline
\end{tabular}

Table 2 Channel flow.

\begin{tabular}{|c|c|c|c|c|c|}
\hline Run & $\varepsilon_{1}$ & $I_{2}$ & $R^{\prime}$ & $T_{R}$ & Remarks \\
\hline 1 & $10^{2}$ & 0 & 1.0 & $\begin{array}{l}3.0,6.0 \\
9.0,12.0\end{array}$ & $\begin{array}{l}\text { Four Sub- } \\
\text { runs }\end{array}$ \\
\hline 2 & $10^{2}$ & 0 & $\left(1-\cos 2 \pi T / T_{R}\right)$ & 25.0 & \\
\hline 3 & $10^{2}$ & 0 & $2\left(1-T / T_{R}\right)$ & 25.0 & \\
\hline 4 & $10^{3}$ & 0 & 1.0 & $\begin{array}{l}2.0,4.0 \\
\quad 6.0,7.2\end{array}$ & $\begin{array}{l}\text { Four Sub- } \\
\text { runs }\end{array}$ \\
\hline 5 & $10^{3}$ & 0 & $\left(1-\cos 2 \pi T / T_{R}\right)$ & $\begin{array}{l}3.6,7.2 \\
14.4\end{array}$ & $\begin{array}{l}\text { Three Sub- } \\
\text { runs }\end{array}$ \\
\hline 6 & $10^{3}$ & 0 & $2\left(1-T / T_{R}\right)$ & $\begin{array}{l}3.6,7.2, \\
14.4\end{array}$ & $\begin{array}{l}\text { Three Sub- } \\
\text { runs }\end{array}$ \\
\hline 7 & $10^{3}$ & $10^{-2}$ & 1.0 & 12.0 & \\
\hline 8 & $10^{3}$ & $10^{-1}$ & 1.0 & 3.0 & \\
\hline 9 & $10^{3}$ & 1.0 & 1.0 & 2.7 & \\
\hline 10 & $10^{3}$ & $10^{-2}$ & $\left(1-\cos 2 \pi T / T_{R}\right)$ & 14.0 & \\
\hline 11 & $10^{3}$ & $10^{-1}$ & $\left(1-\cos 2 \pi T / T_{R}\right)$ & 5.5 & \\
\hline 12 & $10^{3}$ & 1.0 & $\left(1-\cos 2 \pi T / T_{R}\right)$ & 2.7 & \\
\hline 13 & $10^{3}$ & $10^{-2}$ & $2\left(1-T / T_{R}\right)$ & 14.0 & \\
\hline 14 & $10^{3}$ & $10^{-1}$ & $2\left(1-T / T_{R}\right)$ & 5.5 & \\
\hline 15 & $10^{3}$ & 1.0 & $2\left(1-T / T_{R}\right)$ & 2.7 & \\
\hline 16 & $10^{4}$ & 0 & 1.0 & $\begin{array}{l}1.0,2.0, \\
3.0,4.0\end{array}$ & $\begin{array}{l}\text { Four Sub- } \\
\text { runs }\end{array}$ \\
\hline 17 & $10^{4}$ & 0 & $\left(1-\cos 2 \pi T / T_{R}\right)$ & 9.0 & \\
\hline 18 & $10^{4}$ & 0 & $2\left(1-T / T_{R}\right)$ & 9.0 & \\
\hline
\end{tabular}

of outlet condition.

\section{(3) Stability of solution}

Sufficient conditions for the numerical stability of non-linear finite difference equations are not known. In this study, the stability of the solution is checked by the following condition ${ }^{5)}$ suggested by Von-Neumann. ${ }^{3)}$

$$
\mu(|u|+c) \leqq 1,
$$

where $\mu$ is $\Delta t / \Delta x$, and $c=\sqrt{g h}$ is called celerity. 
The above Eq. (23) when transformed to nondimensional quantities takes the following general form.

$$
\frac{\partial T}{\partial X}(|U|+\sqrt{\epsilon H}) \leqq 1 .
$$

Equation (24) is used to check the stability of the solution of both overland and channel flow systems.

The solution is found stable for different magnitudes of $\Delta T$ and $\Delta X$. But here, $\Delta X=0.04$ is kept constant throughout the calculation and $\Delta T$ is varied within the range of 0.0000045 to 0.0045 depending on the magnitudes of $\epsilon_{j}$. The accuracy is checked on the basis of inflow and outflow and a variation of $\pm 2 \%$ is accepted.

\section{(4) Water profile and hydrographs}

\section{a) Water profile}

Fig. 5 shows the non-dimensional water profile of overland flow over horizontal bed under constant rainfall corresponding to several values of $\epsilon_{1}$. The water profiles correspond to equilibrium condition and are almost horizontal for most of the flow length, but bend sharply near the outfall because of assumed free fall condition at the outlet. Fig. 6 shows the equilibrium water profile of overland flow under constant rainfall for several values of slope parameter $I_{1}$ corresponding to $\epsilon_{1}=10^{7}$. For channel, under identical conditions, the water profiles are found to be similar

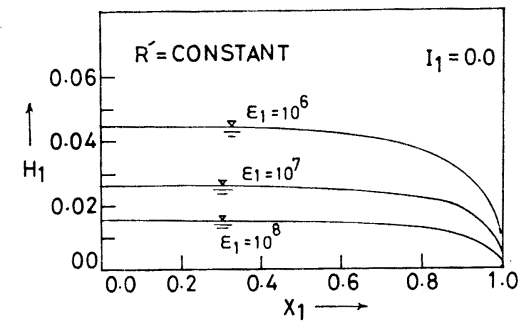

Fig. 5 Water profile of overland flow under equilibrium condition.

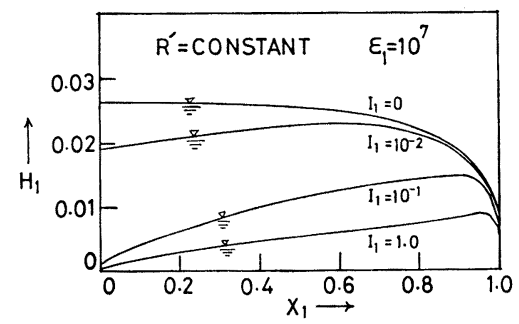

Fig. 6 Equilibrium water profile of overland flow for several values of $I_{1}$. to those for overland. The differences among the water profiles for various slope parameters affect the hydrograph and the storage-discharge relationships as will be discussed later.

b) Discharge hydrographs

Figs. 7, 8 and 9 show the dimensionless discharge hydrographs at the overland outfall for horizontal bed corresponding to rainfall of constant intensity, cosine variation and triangular variation, respectively. Figs. 10, 11 and 12 show the same at the channel outlet under identical conditions. It is noticed that in the case of nondimensional discharge hydrographs time to peak decreases with increasing value of $\epsilon$. Figs. 13, 14 and 15 show the overland discharge hydrographs for sloped beds corresponding to the three types of rainfall patterns mentioned earlier. In this case a constant value of $\epsilon_{1}=10^{7}$ and several

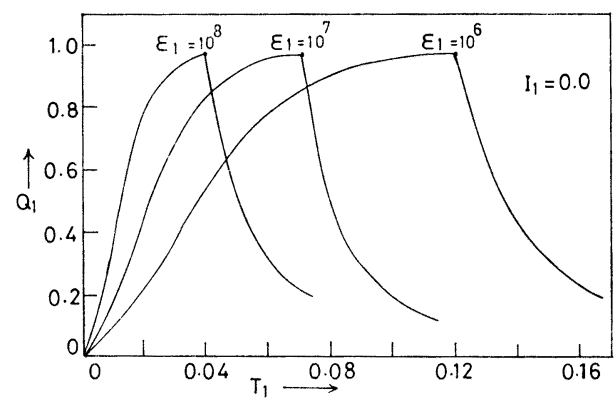

Fig. 7 Discharge hydrographs for constant rainfall (overland).

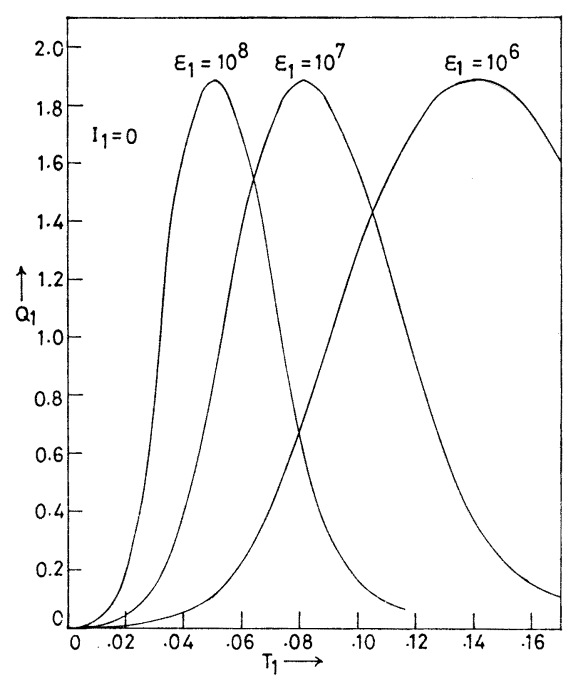

Fig. 8 Discharge hydrographs for rainfall of cosine variation (overland). 


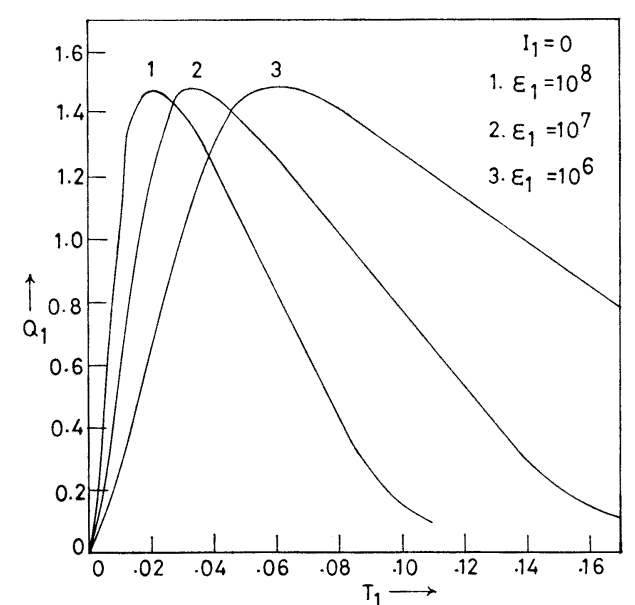

Fig. 9 Discharge hydrographs for rainfall of triangular variation (overland).

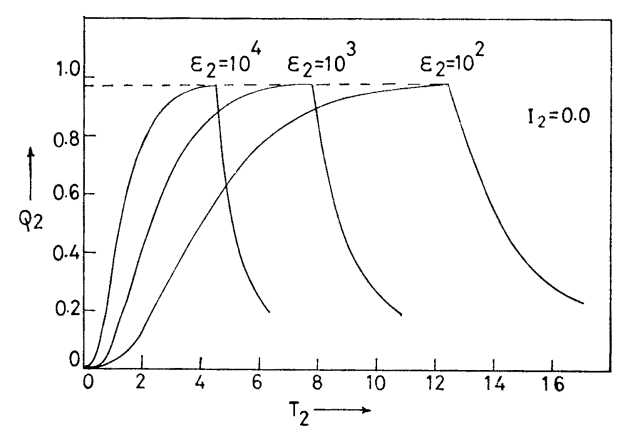

Fig. 10 Discharge hydrographs for constant rainfall (channel).

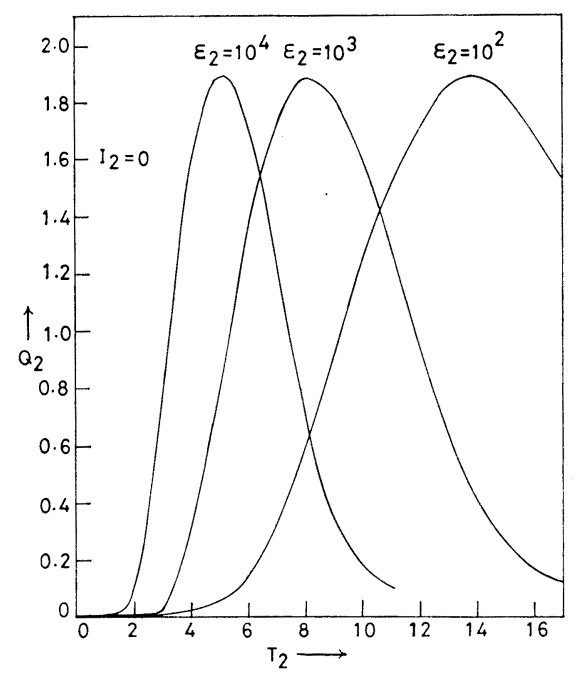

Fig. 11 Discharge hydrographs for rainfall of cosine variation (channel).

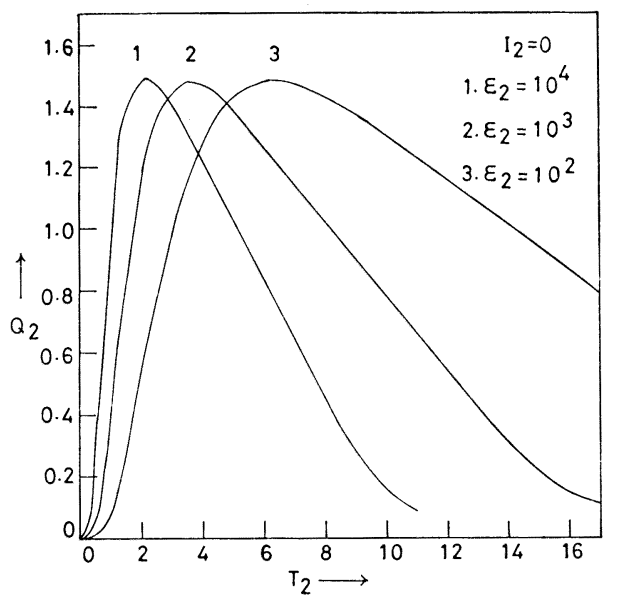

Fig. 12 Discharge hydrographs for rainfall of triangular variation (channel).

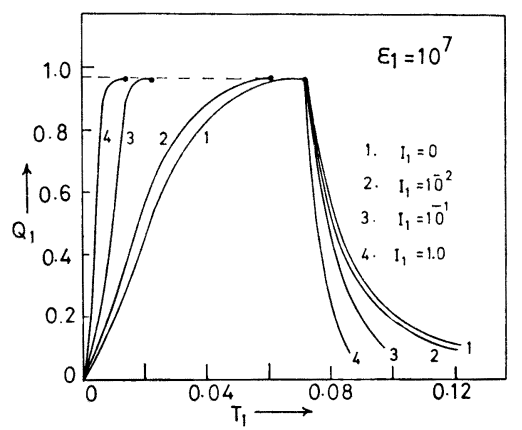

Fig. 13 Overland discharge hydrographs for several values of $I_{1}$ (constant rainfall).

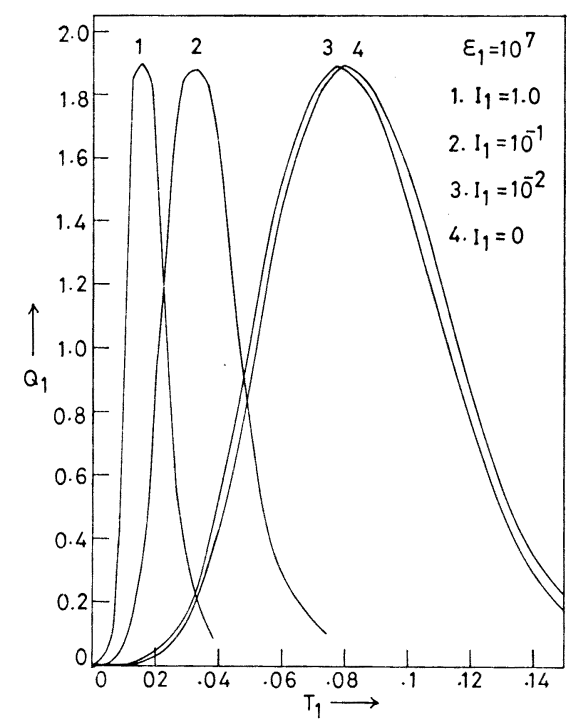

Fig. 14 Overland discharge hydrographs for several values of $I_{1}$ (cosine rainfall). 


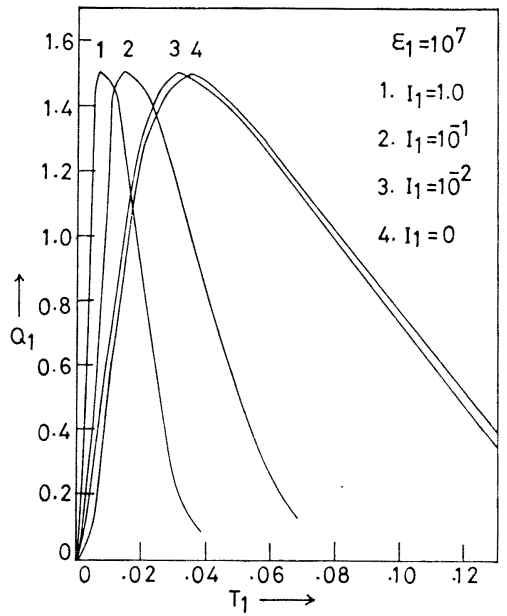

Fig. 15 Overland discharge hydrograph for several values of $I_{1}$ (triangular rainfall).

values of $I_{1}$ are considered. As expected, the rising and recession stages of hydrographs become steeper with increasing value of $I_{1}$. For channel with sloped beds and under identical conditions similar hydrographs are obtained.

All the discharge hydrographs are drawn here corresponding to the equilibrium state of flow. Except in Fig. 13, it is further considered that recession starts immediately after equilibrium state is reached. As such, rainfall duration $T_{R}$ is different for different magnitudes of $\epsilon$.

\section{(5) Storage-discharge curves}

\section{a) Horizontal system $(I=0)$}

The non-dimensional storage and discharge may be expressed, respectively, by the expressions $S_{j}=\int h d x / h_{*} x_{*}$ and $Q_{j}=u h /\left.u_{*} h_{*}\right|_{X=1}$. It may be noted that all the curves in this paper are based on the non-dimensional analysis and the actual shape of the curves in the dimensional form depends on the normalizing operators. Fig. 16 shows the logarithmic plot of nondimensional storage-discharge relation for overland and channel flows for constant rainfall over horizontal beds. The round points in this figure indicate different rainfall durations. It is seen that each storage-discharge relation follows the same rising and recession curves for different durations of rainfall. In overland storage-discharge relation the rising and recession limbs do not differ much. As such, each storage-discharge curve may be replaced by an average dashed line curve. These dashed line curves are

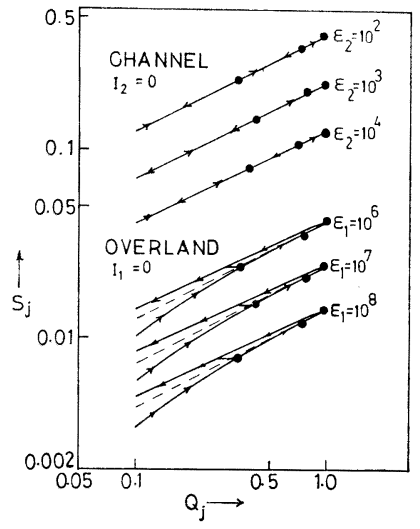

Fig. 16 Logarithmic storage-discharge relation for overland and channel under constant rainfall.

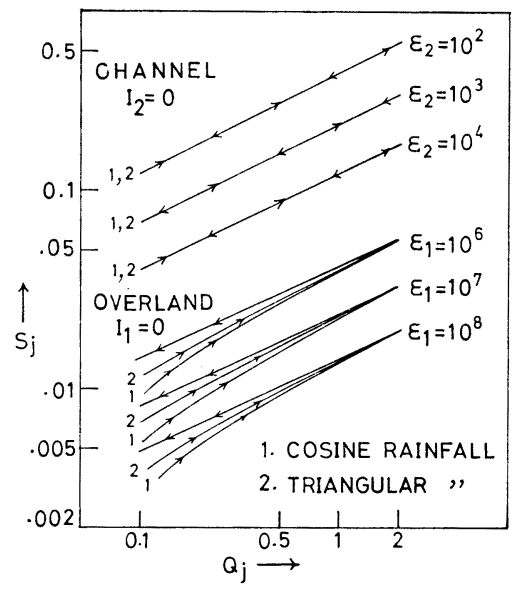

Fig. 17 Logarithmic storage-discharge relation for overland and channel under variable rainfall.

found to be parallel to one another for different values of $\epsilon_{1}$. Also in Fig. 16, the rising and recession limbs of storage-discharge curves for channel are found to be identical and are represented by straight lines which are parallel for different values of $\epsilon_{2}$.

Fig. 17 shows both overland and channel storage-discharge relations on log-log graph paper under variable rainfalls over horizontal bed. For overland, it is seen that for both the cases of variable rainfall the rising and recession limbs are quite close and may be replaced by average straight line curves. In the case of channel flow, the rising and recession limbs are found to be identical and follow the same straight line curve for both the types of variable rainfall. 


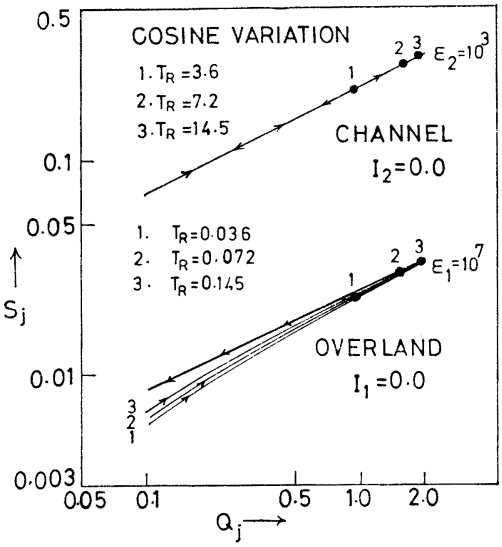

Fig. 18 Logarithmic storage-discharge relation for overland and channel under variable rainfall of different durations.

Fig. 18 shows an example of overland and channel storage-discharge relation for the variable rainfall of different durations. In the case of overland flow the rising limb differs a little with different rainfall durations and the rising limb approaches the recession limb with increasing rainfall duration. The recession limb is, however, not affected by the duration of rainfall. The error involved due to the variation corresponding to different rainfall durations is found to be inappreciable. In the case of channel flow under similar conditions, the rising and recession limbs of storage-discharge curves are found to coincide and follow the same straight line for all durations of rainfall up to the equilibrium stage. As such, channel storage-discharge relation is independent of the duration of rainfall.

Now, it is found that the average storage-discharge curves in Figs. 16, 17 and 18 are all parallel to one another for both overland and channel flows. When different storage-discharge curves are approximated to be straight lines, the following general non-dimensional equation is derived for the overland and channel with horizontal bed.

$$
S_{j}=C \cdot \frac{\sqrt{Q_{j}}}{\epsilon j^{m}}
$$

where $S_{j}$ : non-dimensional storage, $Q_{j}$ : nondimensional discharge, $C$ : non-dimensional storage-discharge coefficient, and $m$ : exponent of $\epsilon j$. From this analysis the magnitudes of $C$ and $m$ recommended are $C=1.0$ and $m=0.233$ for all cases of both overland and channel flows.

b) For sloped bed $(I \neq 0)$

Figs. 19 and 20 show the storage-discharge

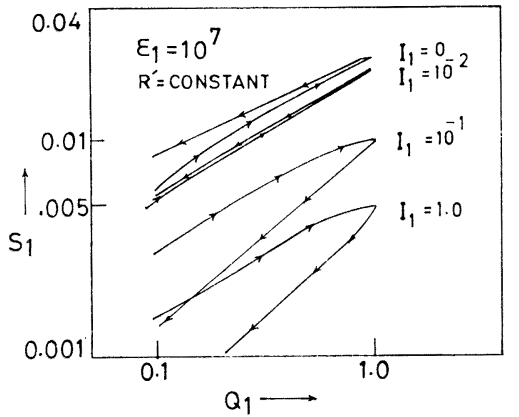

Fig. 19 Logarithmic storage-discharge relation for overland for several values of $I_{1}$.

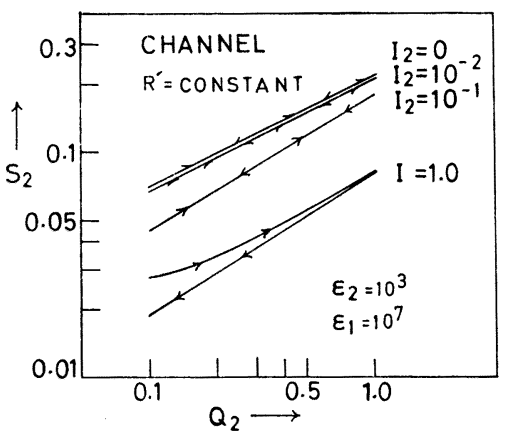

Fig. 20 Logarithmic storage-discharge relation for channel for severl values of $I_{2}$.

relations respectively for the overland and channel flows for constant rainfall over sloped beds. There is an interesting phenomenon in the shape of the curves for the overland flow. For slope parameter $I_{1}=1 \sim 10^{-1}$, at the same discharge, there is more storage during the rising period than in the recession period. For slope parameter $I_{1}=10^{-2}$, at the same discharge, the storage is almost the same for both rising and recession periods. But for $I_{1}=0$ the position of the rising and recession limbs are reversed and at the same discharge there is more storage in recession than in rising. But in the case of channel flow it is seen that the rising and recession limbs are overlapped and are represented by the same line for the slope parameter $I_{2}=0,10^{-2}$ and $10^{-1}$. But for $I_{2}=1.0$, the rising and recession limbs are found to separate and at the same discharge the storage volume is larger in rising than in recession. Fig. 21 shows the overland and channel storage-discharge relation for $I_{1}=I_{2}=10^{-2}$ under the constant rainfall corresponding to several values of $\epsilon_{1}$ and $\epsilon_{2}$. For each case of overland and channel flows, the average storage-discharge 


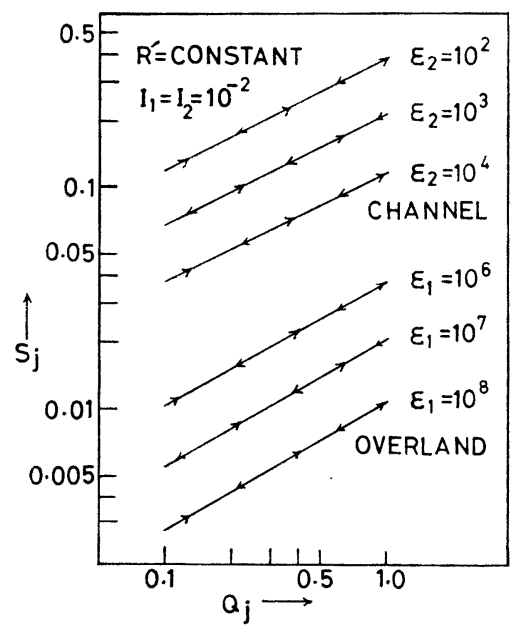

Fig. 21 Logarithmic storage-discharge relation for overland and channel having $I_{1}=$ $I_{2}=10^{-2}$.

curves approximated to be straight lines are found to be parallel to one another. It is found that for slope parameters $I_{1}=I_{2}=10^{-2}$, the storage-discharge relation may be expressed by Eq. (25). For the channel, the same values of $C=$ 1.0 and $m=0.233$ as for the horizontal bed are obtained, but for the overland $C=1.0$ and $m=$ 0.245 are obtained.

\section{DISCUSSIONS}

\section{(1) Storage-discharge relationships}

The derived approximated values of $C=1.0$, $m=0.233$ with respect to Eq. (25) gives an error of $5 \%$ to $10 \%$ at very low discharge for the overland storage-discharge relation in Fig. 16. But, as the discharge increases, the error diminishes and becomes negligible. The channel storagedischarge relations in Fig. 16 may also be expressed by Eq. (25) with negligible error.

If the rising and recession limbs of overland storage-discharge relation as shown in Fig. 17 are approximated to be straight lines, the error in the case of rainfall of cosine variation is found to be comparatively larger than that for triangular variation. Even then, the maximum error in the case of rainfall of cosine variation at very low discharge is in between $5 \%$ to $10 \%$. But this error decreases with increasing discharge and becomes negligible.

Fig. 18 shows an example of variation in the storage-discharge relation for the rainfall of cosine variation of different durations. For over- land, it is seen that for the rainfall of small duration the difference between the rising and recession limbs is comparatively wider than that for rainfall of longer durations. But the difference is so small that it can be neglected without any serious error. The channel storage-discharge relation is, of course, found to be independent of the duration of rainfall. As such, Eq. (25) may be applied to both overland and channel under variable rainfall of any duration.

Fig. 21 shows the storage-discharge relation for overland and channel for slope parameters $I_{1}=$ $I_{2}=10^{-2}$. It is seen that the rising and recession limbs follow the same straight line curves and these may also be represented by Eq. (25).

Although the parameter $m$ has been obtained as $m=0.245$ for overland with $I_{1}=10^{-2}$, however, even if we use the same value of $m=0.233$ as that for $I_{1}=0$, then the resulting difference in the discharge hydrographs for the two cases of $m=$ 0.233 and 0.245 is found to be small and may be neglected. Hence, for practical conveniences it is recommended that the values of $C=1$ and $m=$ 0.233 may be used for both overland and channel systems having the slope parameter from $I=0$ to $I=10^{-2}$.

As described above, the storage-discharge relation is identified into a single functional form with specified coefficient $C$ and exponent $m$, however, for the basin with sloped bed having large value of $I$, the considerable difference between the rising and recession stages is pointed out. The fact has already been observed empirically for the real watershed and has been explained conceptually as depending on the difference in the water surface gradients between the rising and recession stages. Comparing the water profiles with the hydrographs, it may be explained as follows. For the larger value of $I$, the water may flow faster in the rising stage and the water surface profile in an average meaning may become much more steeper than that in the recession stage. On the other hand, for smaller value of $I$ less flow may occur and differences in water surface gradient between the rising and recession stages may becmoe smaller resulting less difference in the two limbs in the $S-Q$ relation.

Even in an actual specified watershed various kinds of $s-q$ relation have been observed due to the various rainfall occurrences. Also in the present paper, even in a specified basin the dimensional $s-q$ relation may be affected slightly by different rainfall intensities in various cases through the normalizing operator $r^{*}$. But, it should 
be emphasized here that, since the operator $r^{*}$ is included in the parameter $\epsilon$, the non-dimensional $S-Q$ relation may be identified for the basin.

\section{(2) Limitation of the applicability}

The storage-discharge relation as expressed by Eq. (25) is expected to be applicable for any pattern of rainfall, for any normal roughness condition of the basin and for any practical flow length. But the applicability of Eq. (25) is limited by the slope parameter. Equation (25) is expected to hold good for any value of slope parameter varying from $I=0$ to $I=10^{-2}$. But for higher values of slope parameter, the difference between the rising and recession limbs in the storage-discharge curves is wider. If for such cases the storage-discharge curves are approximated to be straight lines and Eq. (25) is applied, then the resulting error may be so large that the relation given by Eq. (25) is of no practical significance. As such, it is recommended that Eq. (25) may be applied to overland and channel systems having slope parameter from $I=0$ (horizontal) to $I=10^{-2}$.

\section{(3) Hydrograph estimation as a lumped system}

If the rainfall pattern and the characteristics of a basin are known, time-discharge relation and consequently discharge hydrographs may be obtained with the help of Eq. (25) and the basic continuity equation,

$$
\frac{d S}{d T}=R-Q \text {. }
$$

For the overland flow under constant rainfall the non-dimensional lateral inflow $R=R^{\prime}=1$ for the rising period of hydrograph and $R^{\prime}=0$ for the recession period. Then solving Eqs. (25) and (26) the following results are obtained. For the rising limb of hydrograph

$$
Q=\left\{\frac{e^{2 \kappa T}-1}{e^{2 \kappa T}+1}\right\}^{2}
$$

and for the recession limb

$$
Q=\frac{1}{\left\{1+\kappa\left(T-T_{R}\right)\right\}^{2}}
$$

where $\kappa=\epsilon^{m} / C$. Now $\epsilon$ may be calculated by Eq. (18) and non-dimensional discharge hydrographs may be drawn from Eqs. (27) and (28).

In case of rainfall of cosine and triangular variation, the non-dimensional rainfall $R^{\prime}$ varies with time. Then solving Eqs. (25) and (26) for the variable rainfall the following solution is obtained.

$$
\begin{aligned}
Q(T+\Delta T)= & Q(T)+2 \kappa \sqrt{Q}\left(R^{\prime}-Q\right) \Delta T \\
& +\frac{1}{2}\left\{\frac{\kappa\left(R^{\prime}-Q\right)}{\sqrt{Q}}+2 \kappa \sqrt{Q} \frac{d R^{\prime}}{d T}\right. \\
& \left.-4 \kappa^{2} Q\left(R^{\prime}-Q\right)\right\} \Delta T^{2} . \cdots \cdots \cdots(
\end{aligned}
$$

From Eq. (29) discharge hydrographs for variable rainfall may be obtained. Expressions may similarly be deduced for channel flow and channel hydrographs may be obtained.

The overland discharge hydrographs for the horizontal bed obtained by equations (27), (28) and (29) which represent a lumped system is checked by the computer solution considering a distributed system.

The comparative results are shown in Figs. 22, 23 and 24 for the rainfall of constant intensity,

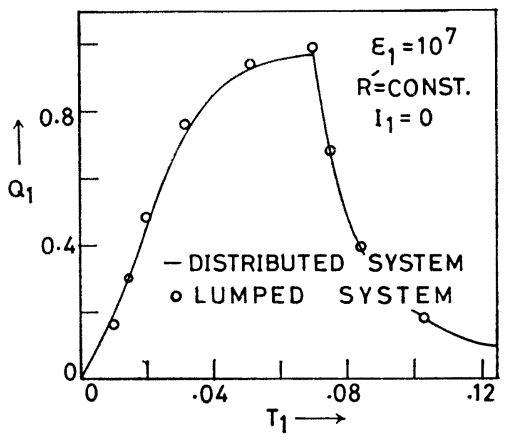

Fig. 22 Overland discharge hydrographs compared under constant rainfall.

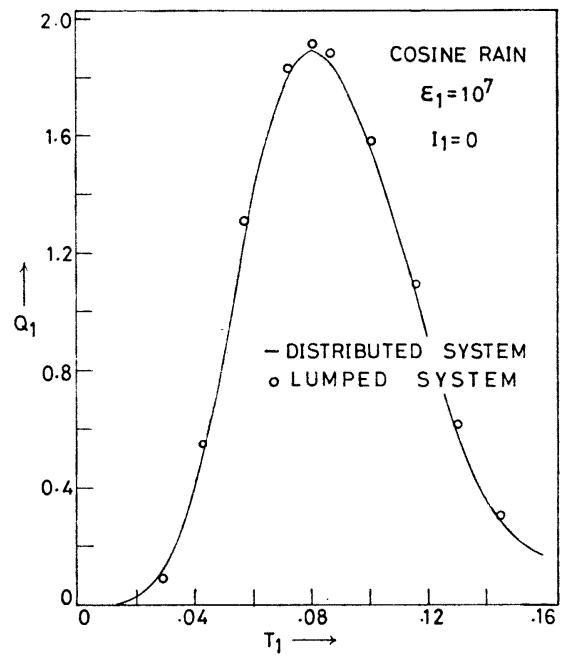

Fig. 23 Overland discharge hydrographs compared under rainfall of cosine variation. 
cosine variation and triangular variation respectively. Fig. 25 shows the overland discharge hydrograph obtained by computer solution for $I_{1}=10^{-2}$ under rainfall of constant intensity and that by Eqsl (27) and (28) with $C=1.0$ and $m=$ 0.233 . The calculations by the two systems are found to agree extremely well, for all the above cases.

\section{(4) Practical use}

In case of conventional storage-discharge relation of $S=k Q^{p}$, the magnitudes of $k$ and $p$ are generally determined from the data of direct field observations. A large number of observed data become necessary with the variation of rainfall pattern and basin characteristics. In this context, the results obtained by this study are of great practical significance. The work involving laborious and time consuming detailed

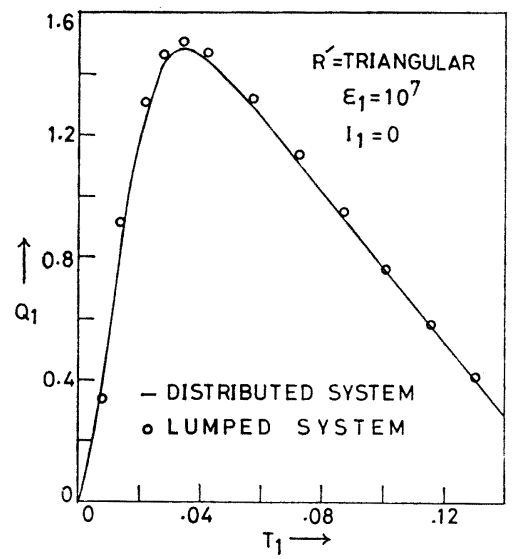

Fig. 24 Overland discharge hydrographs compared under rainfall of triangular variation.

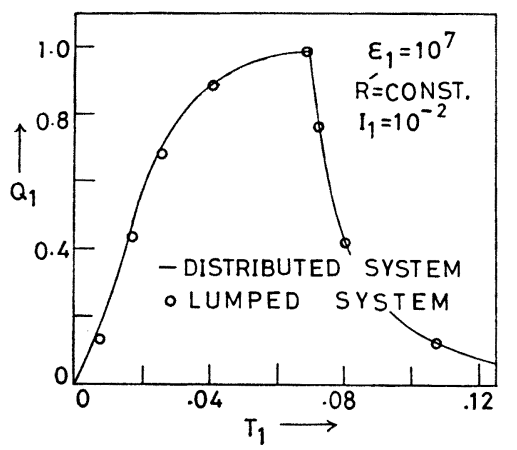

Fig. 25 Overland discharge hydrographs compared for $I=10^{-2}$. calculations and direct field observations to specify the parameters may be greatly reduced. Of course, the actual runoff process includes many complicated factors, but it should be noted here that the essential form of the non-dimensional $S-Q$ relation is expressed in terms of the hydraulic and geographical characteristics. If the rainfall records and basin characteristics are known, the magnitudes of the coefficient and the exponent in storage-discharge relation obtained by the numerical solution of this study may be put to immediate practical use. Overland discharge hydrographs may be prepared with the help of Eqs. (27), (28), and (29). For channel, similar equations may be deduced and applied. The above equations cover a wider range of values for different rainfall patterns and basin characteristics. The only restriction is in the case of slope parameter. The results of this study may be applied with great accuracy to all basins having overland and channel slope parameters varying from $I=0$ to $I=10^{-2}$. To solve the runoff problems in Bangladesh which is predominantly flat and other flat basins around the world this study provides a brief, convenient and direct method which may be put to practical use without difficulties.

The non-dimensional discharge hydrographs obtained with the help of Eqs. (27), (28) and (29) may be converted to dimensional forms by multiplying $Q$ and $T$ by their normalizing operators $q^{*}$ and $t^{*}$. Other hydraulic characteristics e.g. water profile etc. may similarly be converted to dimensional quantities.

\section{CONCLUSIONS}

The following conclusions may be drawn as a result of this study.

1) For overland and channel flow systems over horizontal beds, the parameters $g, n, L$ and $r^{*}$ may be combined together and replaced by a single non-dimensional parameter $\epsilon$ as expressed by Eq. (18). For sloped beds, however, there is an additional parameter $I$ as expressed by Eq. (21).

2) Discharge hydrographs, water profiles, storage-discharge relations etc. for overland and channel basins may be obtained by using an appropriate mathematical model and numerical methods.

3) For the overland and channel having slope parameter varying from $I=0$ to $10^{-2}$, the nondimensional storage-discharge relation is expressed by 


$$
S=C \frac{\sqrt{Q}}{\epsilon^{m}} .
$$

The values of the parameters $m$ and $C$ are estimated as $m=0.233$ and $C=1.0$ for the general use.

4) For the overland and channel having slope parameter from $I=0$ to $10^{-2}$, it is possible to lump the distributed system into a lumped system. It is possible to construct the discharge hydrograph directly from rainfall data and basin characteristics. Other hydraulic behaviours in the flat land may also be analyzed with the help of the non-dimensional expressions for the general cases.

\section{REFERENCES}

1) Abdel-Razaq, Y. Ahmed, Viessman, Warren and J. W. Hernandez: A solution to surface runoff problem, Journ. ASCE, Vol. 93, No. HY 6, Proc. Paper 5606, pp. 335352, Nov. 1967.

2) Chow, V. T.: Open Channel Hydraulics, McGraw Hill Book Co., New York, 1959.

3) Itoh, T.: Application and Fundamentals of Numerical Analysis, Atene Publ. Co., Tokyo, 1971, (in Japanese).

4) Linsley, R. K., Kohler, M. S. and Paulhus, J. L. M., : Applied Hydrology, McGraw Hill Book Co., and Kogakusha Co., Tokyo, 1949.

5) Liggett, J. A. and Woolhiser, D. A.: Difference solutions of shallow water equations,
Journ. of the Engineering Mechanics Division, ASCE, Vol. 93, No. EM 2, Proc. Paper 5189, pp. 39-71, April 1967.

6) Morgali, J. R. and R. K. Linsley: Computer Analysis of Overland Flow, Journal of ASCE, Vol. 91, No. HY 3, Proc. Paper 4325, pp. 81-100, May 1965.

7) Morgali, J. R.: Laminar and Turbulent overland flow hydrograph, Journ. ASCE, Vol. 96, No. HY 2, Proc. Paper 7069, pp. 441-460, Feb. 1970.

8) Somnath, D. and Chow, V. T.: Discussion of Computer Analysis of Overland Flow, ASCE, HY 1, p. 102, Jan. 1966.

9) Suzuki, M. and I. Nishihata: Study on runoff analysis in low-lying land, Proc. JSCE, Vol. 163, pp. 29-37, March 1969, (In Japanese).

10) Toyokuni, E., M. Kadoya and G. Ohhashi: Runoff characteristics of Yamashina river basin, Annuals of Disaster Prevention Research Institute of Kyoto University, No. 8, pp. 297-306, March 1965, (in Japanese).

11) Toyokuni, E. and M. Kadoya: Runoff analysis in paddy field district, Annuals of Disaster Prevention Research Institute of Kyoto University, No. 9, pp. 631-636, March 1966, (in Japanese).

(Received September 11, 1978) 